\title{
Peningkatan Produksi Minyak Sereh Wangi Di Desa Cimungkal-Sumedang
}

\author{
The InCREASEd Production OF OIL Citronella In THE VILlage CimungKal-Sumedang
}

\author{
${ }^{1}$ Nugraha, ${ }^{2}$ Reni Amaranti, ${ }^{3}$ Aviasti, ${ }^{4}$ Aswardi Nasution, ${ }^{5}$ Dini Hariani \\ 1,2,3,4,5 Fakultas Teknik, Universitas Islam Bandung, Jl. Tamansari No. 1 Bandung 40116 \\ e-mail: ${ }^{1}$ nugraha692004@yahoo.com, ${ }^{2}$ reniamaranti2709@yahoo.com
}

\begin{abstract}
Inability to fulfill the demand of consumers is becoming the major issues on citronella oil refinery in the village of Cimungkal Sumedang. This study was conducted to formulate alternative measures in order to increase the production of citronella oil distillates in the Cimungkal village. Mapping of the production process is done with Value Stream Mapping (VSM) as a first step to determine the processing time (lead time of production) and identify the waste that occurs, analyze the causes of the problems at the manufacturing level, and formulate remedial measures to increase the production of oil of citronella. The results show some activity in the production process of citronella oil which is a waste and should be minimized. By mapping, it can be seen that the lead time citronella oil refining initial amounted to 647 minutes or 10.78 hours. After repairs (Future State) improvements Total lead time to 274 minutes. Value-added activity increased by $38.93 \%$, non-value added decreased by $3.63 \%$, and necessary but non-value added fell by $35.3 \%$. The study also resulted in the formulation of strategies that can be done to increase the production of oil of citronella.
\end{abstract}

Keywords: citronella oil, increased production, value stream mapping

\begin{abstract}
Abstrak. Ketidakmampuan memenuhi permintaan dari konsumen menjadi permasalahan utama pada penyulingan minyak sereh wangi di Desa Cimungkal Sumedang. Penelitian ini dilakukan untuk merumuskan alternatif tindakan dalam rangka meningkatkan produksi minyak sereh wangi hasil penyulingan di Desa Cimungkal. Pemetaan proses produksi dilakukan dengan Value Stream Mapping (VSM) sebagai langkah awal untuk mengetahui waktu proses (lead time produksi) dan mengidentifikasi pemborosan yang terjadi, menganalisis penyebab terjadinya masalah di level manufaktur, serta merumuskan tindakan perbaikan untuk meningkatkan produksi minyak sereh wangi. Hasil penelitian menunjukkan ada beberapa aktivitas pada proses produksi minyak sereh wangi yang merupakan pemborosan dan harus diminimalkan. Dengan pemetaan dapat diketahui bahwa lead time penyulingan minyak sereh wangi awal adalah sebesar 647 menit atau 10,78 jam. Setelah dilakukan perbaikan (Future State) terjadi perbaikan Total lead time menjadi 274 menit. Value added activity mengalami peningkatan sebesar 38,93 $\%$, non value added mengalami penurunan sebesar 3,63\%, dan necessary but non value added turun sebesar 35,3 \%. Penelitian ini juga menghasilkan rumusan strategi yang dapat dilakukan untuk meningkatkan produksi minyak sereh wangi.
\end{abstract}

Kata kunci: minyak sereh wangi, peningkatan produksi, value stream mapping

\section{Pendahuluan}

Sereh wangi merupakan salah satu komoditas tanaman di Indonesia yang kaya akan manfaat. Pengembangan tanaman sereh wangi dan pengolahan minyak atsiri dinilai tidak hanya berkontribusi pada pengembangan pertanian, namun juga turut meningkatkan perekonomian masyarakat. Saat ini, wilayah yang menjadi tempat budi daya Sereh Wangi di Jawa Barat diantaranya adalah Gunung Halu, Cililin, Sumedang, 
Subang, Purwakarta dan Lembang Kabupaten Bandung. Semua daerah tersebut menjadi prioritas pemerintah untuk mengembangkan industri minyek sereh wangi.

Permasalahan utama pada industri penyulingan minyak sereh wangi adalah ketidakmampuan para pelaku usaha penyulingan untuk memenuhi permintaan pasar. Oleh karena itu, perlu dirumuskan bagaimana pengembangan industri pengolahan minyak sereh wangi harus dilakukan terutama untuk penyulingan yang skala kecil dan menengah. Hal terpenting dalam upaya pengembangan industri pengolahan minyak sereh wangi adalah peningkatan daya saing minyak sereh wangi melalui perbaikan kualitas, harga yang kompetitif, kontinuitas supply, pembinaan yang terintegrasi, pemanfaatan teknologi tepat guna, mendorong tumbuh kembangnya industri lanjutan, serta meningkatkan kinerja industri penyulingan sereh wangi.

Penyulingan minyak sereh wangi di Desa Cimungkal merupakan salah satu usaha penyulingan minyak sereh wangi yang masih beroperasi di Jawa Barat. Akan tetapi kapasitas penyulingan di desa Cimungkal masih relatif sangat kecil dibanding dengan jumlah permintaan yang ada yaitu sekitar $200 \mathrm{~kg}$ sementara permintaan mencapai 1 ton per bulan. Untuk itu perlu dirumuskan alternatif-alternatif untuk meningkatkan kapasitas produksi penyulingan minyak sereh wangi di desa Cimungkal dan bagaimana upaya tersebut dapat diimplementasikan.

Penelitian-penelitian mengenai sereh wangi telah banyak dilakukan. Penelitianpenelitian tersebut antara lain penelitian mengenai proses pengambilan minyak atsiri dari daun dan batang sereh wangi menggunakan metode distilasi uap dan air dengan pemanasan microwave (Yuni, dkk, 2013), penelitian studi morfologi dan analisis korelasi antar karakter komponen hasil tanaman sereh wangi dalam upaya perbaikan produksi minyak (Djati Waluyo dkk, 2010), penelitian aplikasi perlakuan bahan baku dan penyulingan air-uap terhadap rendemen dan sifat organoleptik minyak atsiri (Marlon L.P., 2012). Penelitian-penelitian lain mempelajari pemanfaatan minyak sereh wangi untuk berbagai tujuan, seperti untuk penolak nyamuk (Dany, 2011), uji toksisitas senyawa sitroneral dari daun sereh wangi sebagai anti feedant terhadap hama thrips pada tanaman jarak pagar (M. Ikbal Fikri, 2010), untuk pengendalian jamur penyebab penyakit tepung pada mentimun (M. Indra Saputra, 2011). Sedangkan penelitian yang dilakukan oleh Retno dkk (2012) membahas mengenai uji finansial terhadap proses isolasi citronellal dan rhodinol pada industri berbasis senyawa turunan minyak sereh wangi dengan objek penelitian pada industri intermediate dari rantai supply minyak sereh wangi. Penelitian mengenai penerapan lean di industri proses diantaranya adalah penelitian yang dilakukan di industri minyak biji kapas (Seth dkk., 2008) dan pada industri minyak atsiri daun cengkeh oleh Effendi dkk. (2008).

Value stream mapping (VSM) merupakan semua aktifitas (yang memberi nilai tambah dan tidak memberi nilai tambah) yang saat ini dibutuhkan untuk membawa sebuah prduk melalui aliran utama yang penting untuk setiap produk : (1) aliran produk dari bahan baku ke tangan pelanggan, dan (2) aliran desain dari konsep hingga diluncurkan (Rother dan Shook, 2003). Liker, et al. (2006) menjelaskan bahwa pemetaan value stream lebih dari sekedar alat yang baik untuk membuat gambaran dalam hal menyoroti pemborosan. Pemetaan membantu kita melihat rangkaian proses yang saling terkait dan untuk membayangkan value stream di masa mendatang. Tujuannya adalah memperbaiki setiap proses untuk mendukung proses yang mengalir. Setiap perusahaan harus memiliki pemahaman yang menyeluruh mengenai konsep dasar dan bagaimana menciptakan proses yang mengikuti konsep tersebut. Analisis proses dilakukan dengan mengumpulkan data dari berbagai pertanyaan dengan keahlian di lantai perusahaan, pekerja yang langsung berpartisipasi dalam mengukur waktu 
berbagai proses (Belokar, et al., 2012). Terdapat (tujuh) elemen yang mungkin dapat digunakan dalam perbaikan pemetaan value stream atau dalam peningkatan kaizen yang lebih spesifik dan terus menghilangkan pemborosan, diantaranya (Liker, et al., 2006) adalah fleksibilitas, lead time yang singkat, proses yang saling terhubung, putaran aliran, aliran informasi yang disederhanakan, kesadaran akan permintaan pelanggan, dan penentu kecepatan.

Pada umumnya dalam pengolahan minyak atsiri, dikenal 3 macam metode penyulingan, yaitu (1) penyulingan dengan air (water distillation) yang merupakan metode paling mudah dibandin metode lainnya, (2) penyulingan dengan air dan uap (water and steam distillation) yang disebut sistem kukus dan menghasilkan rendemen minyak lebih banyak dibanding dengan metode penyulingan dengan air, dan (3) penyulingan dengan uap (steam distillation).

\section{Metodologi Penelitian}

Tahapan penelitian yang dilakukan adalah pengumpulan data dengan survey lapangan dan mengumpulkan data sekunder dengan mengumpulkan data dari dinas perkebunan dan dinas pertanian serta dari sumber-sumber lain yang relevan dengan topik penelitian. Pemetaan proses produksi minyak sereh wangi dengan value stream mapping membantu untuk mengidentifikasi jenis-jenis pemborosan yang terjadi sepanjang proses, analisis penyebab pemborosan dilakukan dengan menggunakan diagram ishikawa, serta akhirnya dirumuskan tindakan perbaikan yang dapat dilakukan agar kapasitas produksi penyulingan minyak sereh wangi di Desa Cimungkal dapat meningkat. Untuk dapat memperkuat hasil analisis dan hasil penelitian sepanjang tahapan penelitian disertai dengan penelaahan teori atau literatur yang mendukung sebagai referensi dari semua tahapan yang dilakukan.

\section{Hasil dan Pembahasan}

Pelaku rantai pasok sereh wangi di desa Cimungkal terdiri atas petani sereh, pengepul yang merupakan penyuling, perusahaan Manufaktur yang memproduksi produk dengan bahan baku minyak sereh wangi. Petani sereh wangi merupakan orang yang bertanggung jawab dalam menyelesaikan pekerjaan mulai dari mempersiapkan lahan, menanam sereh wangi, merawat tanaman, hingga memanen sereh wangi. Petani sereh wangi di desa Cimungkal saat ini berjumlah 10 orang dengan luas masing-masing wilayah bertani sebesar 1 hektar. Petani-petani ini mendapatkan sarana dan prasarana yang disediakan oleh pengepul sebagai modal bertani sereh wangi dengan status meminjam. Kemudian hasil panen dijual kembali kepada pemberi modal dengan keuntungan yang menjanjikan untuk petani. Perusahaan yang dituju untuk menjual minyak sereh wangi terdiri atas 3 perusahaan besar, yaitu PT Indesso Aroma, PT Djasulawangi dan PT Pan Aroma. Ketiga perusahaan ini memiliki permintaan sama besar yaitu satu ton per bulan.

Budidaya sereh wangi dilakukan dengan tahapan pembibitan, pencangkulan, penanaman, penyiangan, pemupukan dan panen. Untuk menghasilkan minyak sereh wangi tersebut, masing-masing petani harus meanam bibit dengan waktu menunggu selama 5-6 bulan untuk hasil panen pertama dan 3 bulan untuk masa panen selanjutnya. Kemudian hasil panen dikumpulkan dan dikirim ke penyulingan minyak sereh wangi. Penyulingan minyak sereh wangi di desa Cimungkal Sumedang saat hanya mampu memenuhi $6,7 \%$ dari total permintaan. 
Tabel 1 Waktu Proses penyulingan sereh wangi

\begin{tabular}{|c|l|c|c|}
\hline No & \multicolumn{1}{|c|}{ Aktivitas } & $\begin{array}{c}\text { Jarak } \\
(\mathbf{m})\end{array}$ & $\begin{array}{c}\text { Waktu } \\
(\mathbf{m e n i t})\end{array}$ \\
\hline $\mathbf{1}$ & Bahan baku diterima & 0 & 60 \\
\hline $\mathbf{2}$ & Bahan baku di bawa ke tempat menimbang & 2 & 3 \\
\hline $\mathbf{3}$ & Bahan baku di letakan di tempat menimbang & 0 & 10 \\
\hline $\mathbf{4}$ & Bahan baku ditimbang & 0 & 30 \\
\hline $\mathbf{5}$ & Bahan baku dibawa ke tempat penjemuran dan dihamparkan & 8 & 30 \\
\hline $\mathbf{6}$ & Bahan baku ditunggu selama 4 jam & 0 & 240 \\
\hline $\mathbf{7}$ & Memanaskan mesin & 0 & 60 \\
\hline $\mathbf{8}$ & Bahan baku di bawa ke mesin & 7 & 7 \\
\hline $\mathbf{9}$ & Bahan baku di masukan ke mesin & 0 & 5 \\
\hline $\mathbf{1 0}$ & Katel atau mesin ditutup & 0 & 2 \\
\hline $\mathbf{1 1}$ & Bahan baku diproses & 0 & 180 \\
\hline $\mathbf{1 2}$ & minyak yang keluar dibiarkan hingga dingin & 0 & 10 \\
\hline $\mathbf{1 3}$ & minyak dan air diambil untuk dilakukan pemisahan & 0 & 1 \\
\hline $\mathbf{1 4}$ & minyak dikemas dimasukan ke dalam dirigen & 0 & 4 \\
\hline $\mathbf{1 5}$ & dirigen ditutup & 0 & 1 \\
\hline $\mathbf{1 6}$ & dirigen disimpan & 10 & 4 \\
\hline
\end{tabular}

Penggambaran dan pemetaan proses penyulingan minyak sereh wangi (menggunakan value stream mapping) merupakan langkah awal untuk mengidentifikasi lead time produksi dan jenis-jenis pemborosan yang terjadi sepanjang aliran proses. Perbaikan produksi ini dimaksudkan untuk meminimasi pemborosan pada kegiatan penyulingan sehingga waktu penyulingan dapat direduksi dan memperbaiki produktivitas penyulingan sereh wangi. Hasil pemetaan proses penyulingan akan menjadi dasar untuk perbaikan proses di level manufaktur pada rantai pasok yang akan berpengaruh juga pada peningkatan produktivitas rantai pasok secara keseluruhan.

Penyulingan minyak sereh wangi di Cimungkal memiliki tiga konsumen besar dengan permintaan secara periodik sebanyak 1 ton. Kualitas minyak sereh wangi diukur setiap kali proses pembelian dan menentukan harga beli. Sedangksan aliran informasi dimulai dari konsumen, pengepul atau penyuling dan petani sereh wangi dan sebaliknya.

Aliran fisik atau aliran material yang terjadi adalah (1) proses penerimaan bahan baku; (2) proses penimbangan sereh wangi yang masih basah dari petani; (3) proses penjemuran sereh wangi hasil panen dengan cara dihamparkan setipis mungkin pada tempat penjemuran selama 3-4 jam; (4) pemanasan ketel penyulingan dengan merebus air/aquades yang terletak pada sisi bawah ketel; (5) proses penyulingan dengan menggunakan katel kapasitas 1 ton selama 3 jam; (6) proses pemisahan hasil uap air dan minyak sereh wangi yang dihasilkan dengan cara disaring; dan (7) pengemasan dan penyimpanan minyak ke dalam jerigen.

Hasil penggambaran dengan Value Stream Mapping untuk sistem yang terjadi saat ini dijelaskan pada gambar 1 . 


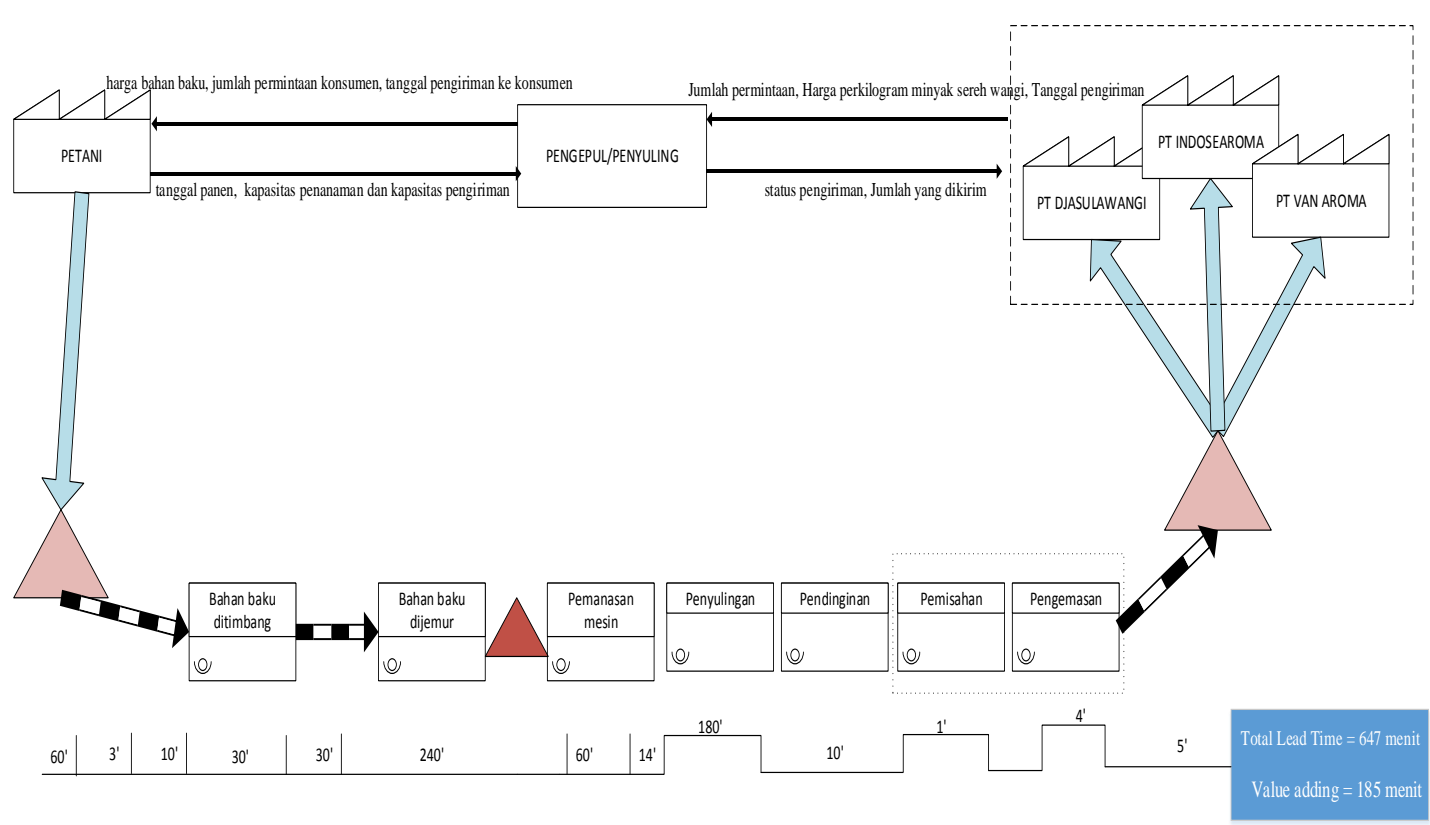

Gambar 1. Big Picture Mapping - Current State Map

Dari gambar di atas dapat dilihat bahwa Total lead time penyulingan minyak sereh wangi sebesar 647 menit dengan value added activity sebesar 185 menit, non value added activity 40 menit, dan necessary but non value added activity sebesar 422 menit.

Dari semua kegiatan tersebut kemudian dikelompokkan jenis-jenis pemborosan (waste) yang terjadi. Pemborosan yang teridentifikasi adalah waiting (pengumpulan sereh wangi, serehwangi diangin-anginkan sebelum disuling, dan proses pemanasan mesin), transportation (pemindahan sereh wangi ke tempat penimbangan, pemindahan ke tempat penjemuran, pemindahan ke mesin penyulingan, dan penyimpanan jerigen), dan unnecessary motion (penyimpanan bahan baku di tempat penimbangan dan penimbangan sereh wangi). Perbaikan proses atau aktivitas usulan pada proses penyulingan minyak sereh wangi digambarkan pada value stream mapping -future state map (Gambar 2). Langkah berikutnya adalah mengidentifikasi penyebab pemborosan, yang secara garis besar disebabkan oleh prosedur kerja yang kurang teratur dan minimnya penggunaan alat bantu. Aktivitas usulan yang digambarkan pada gambar 2 dapat dilakukan jika cara kerja dan penggunaan alat bantu diperbaiki (perancangan alat bantu dan metode kerja akan diteliti pada penelitian selanjutnya).

Langkah terakhir yang dilakukan adalah merumuskan strategi peningkatan kapasitas atau peningkatan produksi minyak sereh wangi (Tabel 2). Dasar perumusan strategi adalah pemenuhan demand yang saat ini belum terpenuhi dengan optimal. Strategi yang diambil pada dasarnya terbagi menjadi dua strategi utama yaitu meningkatkan jumlah produksi dengan mengoptimalkan sarana penyulingan yang telah ada saat ini dan memaksimalkan produksi untuk memenuhi demand. 


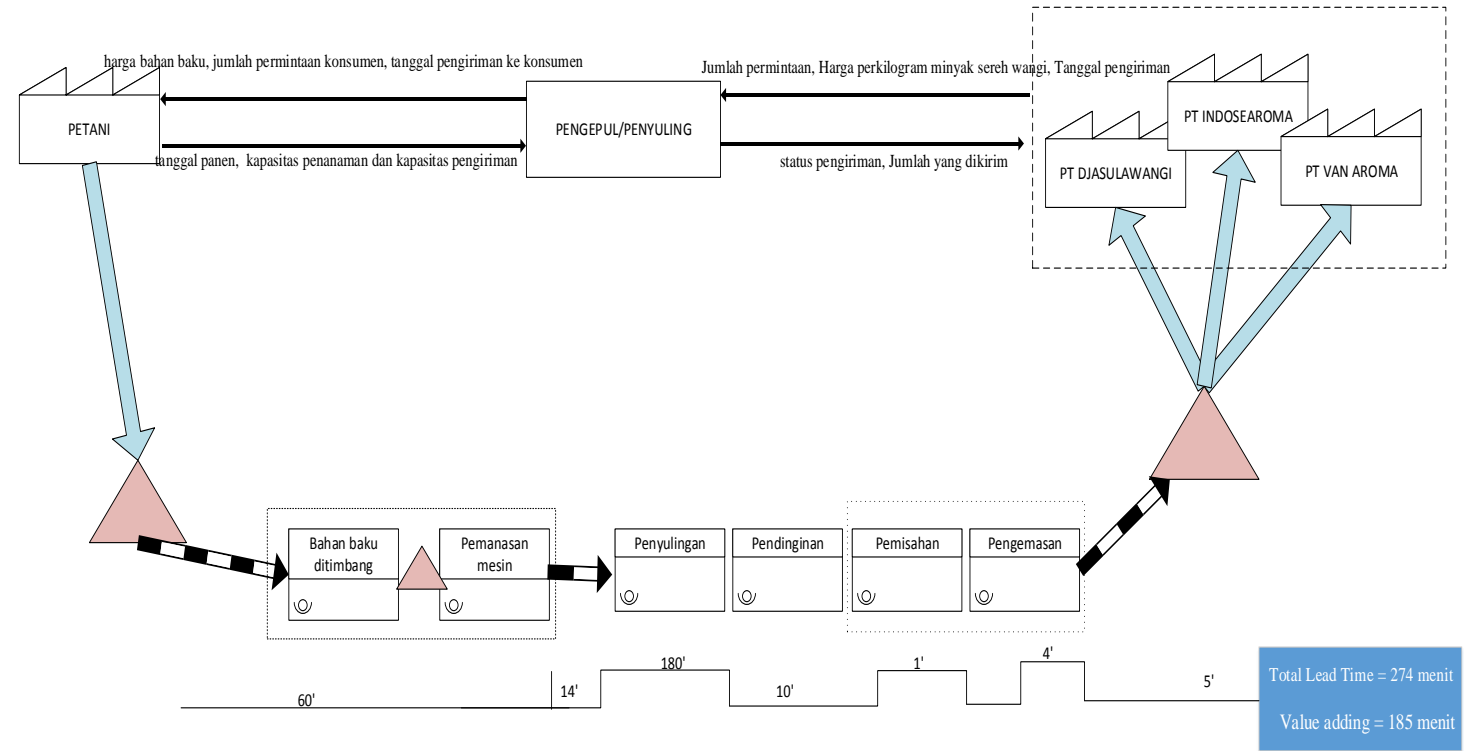

Gambar 2. Value Stream Mapping - Future State Map

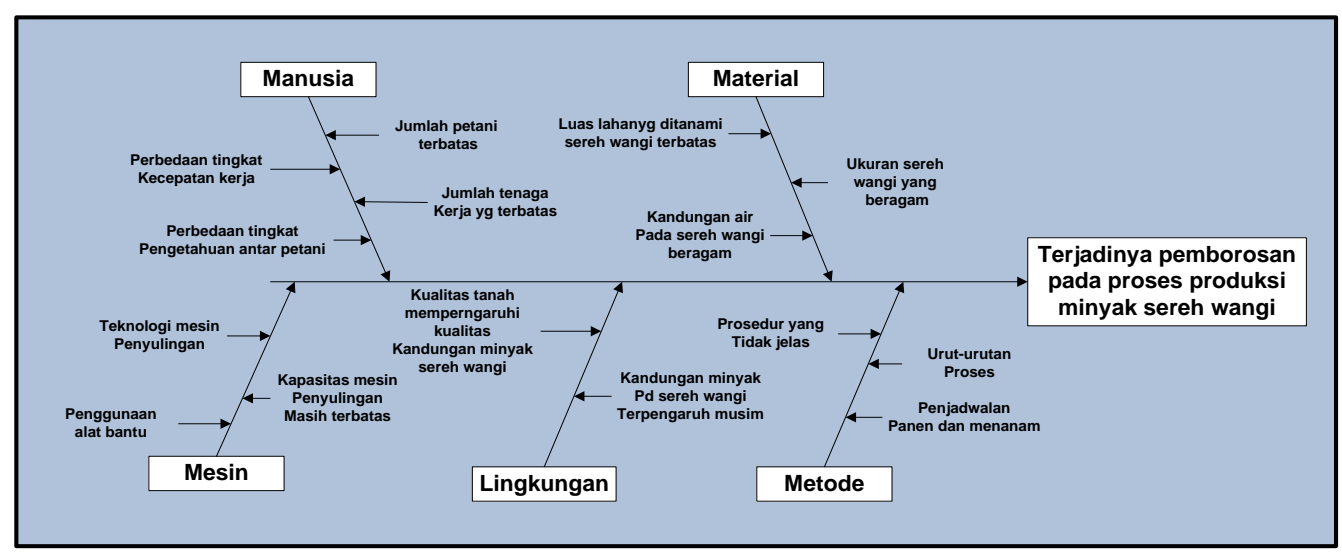

Gambar 3. Penyebab pemborosan

Tabel 2 Alternatif strategi untuk meningkatkan produksi minyak sereh wangi

\begin{tabular}{|c|c|c|c|c|}
\hline Alternatif Strategi & $\begin{array}{c}\text { Kapasitas } \\
\text { Penyulingan yang } \\
\text { dibutuhkan }\end{array}$ & $\begin{array}{l}\text { Kebutuhan } \\
\text { bahan baku } \\
\text { sereh wangi }\end{array}$ & $\begin{array}{c}\text { Kebutuhan lahan } \\
\text { budidaya sereh } \\
\text { wangi }\end{array}$ & Implementasi \\
\hline $\begin{array}{l}\text { Memaksimalkan } \\
\text { kapasitas fasilitas } \\
\text { penyulingan yang } \\
\text { ada saat ini } \\
\text { ( } 1 \text { mesin } \\
\text { penyulingan dan } 25 \\
\text { hari kerja/bulan) }\end{array}$ & $\begin{array}{l}\text { - Jumlah Mesin : 1 } \\
\text { - Kapasitas/hari = } \\
3 \times 4=12 \mathrm{~kg} \text { minyak } \\
\text { / hari } \\
\text { - Jumlah hari/bulan = } \\
25 \text { hari } \\
\text { - Kapasitas per bulan } \\
=12 \mathrm{~kg} \times 25 \\
=300 \mathrm{~kg}\end{array}$ & $\begin{array}{l}- \text { Per hari }= \\
3 \mathrm{x} 1 \text { ton }= \\
3 \text { ton } / \text { hari } \\
\text { Bahan baku } \\
/ \text { bulan }= \\
3 \times 25=75 \\
\text { ton }\end{array}$ & $\begin{array}{ll}- & 1 \mathrm{Ha}=10 \text { ton } \\
& \text { sereh wangi } \\
\text { - } & \text { } a h a n \text { per bulan }= \\
75 / 10=7,5 \mathrm{Ha} \\
\text { - } \\
\text { Karena panen } 3 \\
\text { bulan sekali maka } \\
\text { luas lahan yg } \\
\text { diperlukan }=7,5 \mathrm{x} \\
3=22,5 \mathrm{Ha}\end{array}$ & $\begin{array}{l}\text { Dapat dilakukan dengan } \\
\text { cara: } \\
\text { - Memenuhi kebutuhan } \\
\text { bahan baku dengan cara } \\
\text { membeli sereh wangi dari } \\
\text { daerah lain } \\
\text { - Membuka lahan baru } \\
\text { sehingga luas lahan yang } \\
\text { ditanami sereh wangi } \\
\text { sekitar } 22,5 \mathrm{Ha} \\
\end{array}$ \\
\hline $\begin{array}{l}\text { Memaksimalkan } \\
\text { penggunaan lahan } \\
\text { yang telah ada } \\
\text { walaupun belum } \\
\text { semua digunakan } \\
\text { (jika lahan yg } \\
\text { digarap 45 Ha) }\end{array}$ & $\begin{array}{l}\text { - Bahan baku yang } \\
\text { tersedia } 6 \text { ton/hari } \\
\text { - Penyulingan yang } \\
\text { dilakukan/hari = } 3 \\
\text { kali } \\
\text { - Kapasitas mesin / } \\
\text { hari }=12 \mathrm{~kg} \text { minyak } \\
\text { sereh wangi dari } \\
\text { bahan baku } 3 \text { ton } \\
\text { - Jumlah mesin : } 2\end{array}$ & $\begin{array}{l}\text { Total bahan } \\
\text { baku yang } \\
\text { tersedia }=150 \\
\text { ton / bulan } \\
\text { Atau } \\
6 \text { ton/hari }\end{array}$ & $\begin{array}{l}\text { Luas lahan yang } \\
\text { digarap }=3 \times 15=45 \\
\text { Ha }\end{array}$ & \multirow{2}{*}{$\begin{array}{l}\text { Dapat dilakukan dengan } \\
\text { cara : } \\
\text { - Menambah mesin } \\
\text { penyulingan yang ada } \\
\text { menjadi } 2 \\
\text { - Mengatur waktu tanam } \\
\text { setiap Ha lahan garapan } \\
\text { agar panen dapat } \\
\text { dilakukan secara } \\
\text { kontinyu } \\
\text { - Menambah jumlah petani } \\
\text { yang terlibat dan } \\
\text { membentuk kelompok } \\
\text { tani untuk keberlanjutan } \\
\text { budidaya sereh wangi }\end{array}$} \\
\hline $\begin{array}{l}\text { 3. Menetapkan target } \\
\text { produksi per bulan } \\
\text { sebanyak } 1 \text { ton } \\
\text { minyak sereh } \\
\text { wangi ( } 1 / 3 \\
\text { permintaan atau } \\
\text { permintaan untuk } 1 \\
\text { perusahaan }) \\
\end{array}$ & $\begin{array}{l}\text { Jumlah mesin yg } \\
\text { harus tersedia }= \\
1000 / 300= \pm 4 \text { mesin }\end{array}$ & $\begin{array}{l}\text { Bahan baku } \\
\text { yang harus } \\
\text { tersedia }=4 \times \\
3 \times 1=12 \text { ton } \\
\text { Atau } \\
12 \times 25=300 \\
\text { ton / bulan }\end{array}$ & $\begin{array}{l}\text { Luas lahan yang } \\
\text { tersedia }=30 \mathrm{Ha} \times 3 \\
=90 \mathrm{Ha}\end{array}$ & \\
\hline
\end{tabular}




\section{Kesimpulan}

Hasil pemetaan proses penyulingan menggambarkan bahwa masih terdapat kegiatan yang saat ini dilakukan akan tetapi tidak bernilai tambah pada produktifitas sehingga kemungkinan perbaikan untuk meningkatkan kapasitas penyulingan atau peningkatan produksi minyak sereh wangi masih terbuka lebar. Total lead time yang digunakan untuk melakukan penyulingan hingga mencapai 647 menit atau 10,78 jam untuk proses penerimaan, penjemuran dan penyulingan sebanyak satu kali. Perbaikan (Future State) menghasilkan perbaikan Total lead time menjadi 274 menit. Value added mengalami peningkatan sebesar 38,93\% menjadi 67,52\% dari sebelumnya. Untuk non value added mengalami penurunan sebesar 3,63\% menjadi $2,55 \%$ dan necessary but non value added juga mengalami penurunan sebesar 35,3\% menjadi $29,93 \%$.

Dari tiga alternatif strategi yang dirumuskan, alternatif 1 merupakan strategi yang paling mungkin dapat diimplementasikan dalam waktu dekat (target jangka pendek), sedangkan alternatif 2 dan 3 memerlukan upaya lebih keras lagi untuk dapat mengimplementasikannya. Walaupun demikian, dengan menggambarkan alternatif 2 dan 3, masyarakat yang terlibat pada penyulingan minyak sereh wangi di desa Cimungkal dapat mengetahui kemungkinan pengembangan yang dapat dilakukan. Alternatif 2 dan 3 dapat dilakukan secara bertahap apabila semua entitas dalam rantai pasok berkontribusi maksimal.

Untuk peningkatan kapasitas produksi atau perbaikan rantai pasok penyulingan sereh wangi di daerah Cimungkal perlu dilakukan upaya-upaya yang berkesinambungan antara pelaku usaha, petani, dan pemerintah. Pada masa yang akan datang perlu dibentuk kelompok tani yang akan bekerja sama untuk mengelola lahan seluas kurang lebih 100 Hektar yang diberikan hak kelola oleh pemerintah untuk ditanami sereh wangi yang saat ini belum dikelola secara maksimal oleh petani di Cimungkal. Penjadwalan masa tanam dan panen harus diatur sedemikian rupa sehingga ketersediaan bahan baku dapat kontinyu setiap bulan dan petani juga mendapatkan manfaat yang rutin per bulan dari hasil menanam sereh wangi.

Untuk penelitian selanjutnya perlu dipertimbangkan dengan lebih detail analisis keuangan dari berbagai skenario dari usulan pada penelitian ini atau jika memungkinkan juga ditelaah mengenai bagaimana sebaiknya model industri penyulingan ini dibuat agar dihasilkan industri yang berkelanjutan dan berwawasan lingkungan. Penelitian lain yang dapat dilakukan adalah perancangan metode kerja dan alat bantu yang dapat digunakan untuk berbagai aktivitas yang dilakukan pada penyulingan minyak sereh wangi (alat bantu untuk petani atau alat bantu untuk penyuling pada level manufaktur).

\section{Daftar pustaka}

Aviasti, 2010. Model simulasi simbiosis industri gula dan industri pupuk dalam eco industrial park. Karya Ilmiah. Dipresentasikan dalam seminar Nasional Penelitian Masalah Lingkungan di Indonesia VI di Universitas Udayana. Bali.

Belokar, R.M., Kharb, S.S., Kumar, V., 2012. An Application of Value Stream Mapping in Automobile Industry : A Case Study. International Journal of Innovative Technology and Exploring Engineering (IJITEE) [Accessed 20 Mei 2016]

Chertow, M.R., 2000, Industrial symbiosis: Literature and taxonomy. Annual Review of Energy and the Environmental, Proquest Science Journals. 25, 313-337.

Chertow, M.R., 2007, Uncovering industrial symbiosis, Journal of Industrial Ecology, 11(1), 11-30. 


\section{2 | Nugraha, et al.}

Danny Parawita Lubis, 2011, Uji Aktivitas Penolak Nyamuk Dari Minyak Atsiri Daun Tumbuhan Sereh Wangi (Cymbopogon nardus (L.)Rendle) Dalam Sedian Lotion, Skripsi, Fakultas Farmasi Universitas Sumatera Utara

Djati Waluyo Djoar, Panut Sahari, dan Sugiyono, Studi Morfologi dan Analisis Korelasi Antar Karakter Komponen hasil Tanaman Sereh Wangi (Cymbopogon sp.), Skripsi, Fakultas Pertanian UNS, Surakarta.

Egi Aguatian, Anny Sulaswaty, Tasrif, Joddy Arya L., dan Indri Badria, Pemisahan Citronellal dari Minyak Sereh Wangi Menggunakan Unit Fraksionasi Skala Bench, Jurnal Tek. Industri Pertanan, Vol. 17(2), hal 45-53.

Fawcett, S.E., Ellarm, L.M., dan Ogden, J.E., 2007. Supply Chain Management : From Vision to Implementation. New Jersey :Pearson Education

Harris, S., 2007, Industrial symbiosis in the Kwinana industrial area (Western Australia). Australia.

Inaas Azmi Haidar, 2011, Uji Efektivitas Ekstrak Serai Wangi (Cymbopogon nardus) Sebagai Insektisida Terhadap Nyamuk Aedes Aegypti Dengan Metode Fogging , Tugas Akhir, Fakultas Kedokteran Universitas Brawijaya.

Lambert, D.M., 2006. Supply Chain Management : Process, Partnership, Performance. $2^{\text {nd }}$ ed. Jacksonville : Supply Chain Management Institute

Lasa, I.S., Laburu, C.O., dan Vila, R.C., 2008. An Evaluation of The Value Stream Mapping Tool. Bussines Process Management Journal, 14(1), 39-52. < www.emeraldinsight.com>

Liker, Jeffrey K. dan Meier, David., 2006. The Toyota Way Field Book (Panduan untuk mengimplementasikan Model 4P Toyota). Jakarta : Erlangga.

Maia, C.L., Alves, A.C., dan Leao, C.P., 2012. Sustainable Work Environment with Lean Production in Textile and Clothing Industry, [e-journal] 4(3), pp.183-190. Available online at www.iim.ftn.uns.ac.rs/ijiem journal.php

M. Dzikron dan Aswardi Nasution, (2012), Perbaikan proses produksi dan penerapan teknologi tepat guna bagi Pengrajin Emping Singkong di desa Cijambe, Kab. Sumedan, Laporan Akhir IbM, Hibah Desentralisasi Dikti, Kemendiknas.

Nasution, A. , 2014, Pemanfaatan Potensi Lokal Desa Tanjung Wangi Kecamatan Cicalengka melalui wirausaha Sereh Wangi. Prosiding Hibah Pengabdian Kepada Masyarakat (PKM). Bandung: Universitas Islam Bandung

Owi Setyaningsih. Erliza Hambali, dan Muharamia Nasution, Aplikasi Minyak Sereh Wangi (Citronella Oil) dan Geraniol Dalam Pembuatan Skin Lotion Penolak Nyamuk, Jurnal Teknologi Industri Pertanian, Volume 17 (3), hal. 97-103

Retno Sri Indah L., Djumali M., Ani S., Anas Miftah, dan Meika Syahbana R., 2012, Kajian Finansial Isolasi Citronellal dan Rhodinol Pada Industri Berbasis Senyawa Turunan Minyak Sereh Wangi, Agrointek Volume 6 Nomor 1, hal. 45-54.

Rohimatun dan I Wayan Laba, 2013, Efektifitas Insektisida Minyak Sereh Wangi dan Cengkeh Terhadap Hama Pengisap Buah Lada (Dasynus Piperis China), Buletin Littro, Volume 24 Nomor 1.

Rother, M., dan Shock, J., 1999. Learning To See: Value Stream Mapping To Create Value and Eliminate Muda. Brookline, MA : The Lean Enterprise Institute.

Supriyanto, 2000, Potensi Ekstrak Sereh Wangi (Cymbopogon Nerdus L) Sebagai Anti Streptoccus Mutans, Skripsi, Program Studi Biokimia Fakultas MIPA IPB.

Yuni Eko F, Patar Jonathan S., Mahfud, dan Pantjawarni P., 2013, Pengambilan Minyak Atsiri dari Daun dan Batang Serai Wangi (Cymbopogon Winterianus) Menggunakan Distilasi Uap dan Air dengan Pemanasan Microwave, Jurnal Teknik POMITS, Vol 2 No 1, ISSN 2337-3539 (2301-9271) 